\title{
Changing Student Perception of an Online Integrated Structured Clinical Examination During the COVID-I9 Pandemic [Response to Letter]
}

\author{
Sashiananthan \\ Ganesananthan (iD) ${ }^{1-3}$ \\ Chunhei $\mathrm{Li}^{4}$ \\ Timothy Woo ${ }^{5}$ \\ Anastasia Donnir ${ }^{6}$ \\ Anthony Wijaya $^{7}$ \\ Ankur Khajuria ${ }^{8,9}$ \\ 'West Middlesex University Hospital, \\ Chelsea and Westminster NHS \\ Foundation Trust, London, UK; \\ ${ }^{2}$ Department of Metabolism, Digestion \\ and Reproduction, Faculty of Medicine, \\ Imperial College London, London, UK; \\ ${ }^{3}$ National Heart and Lung Institute, \\ Imperial College London, London, UK; \\ ${ }^{4}$ St George's Hospital, St George's \\ University Hospital NHS Foundation \\ Trust, London, UK; ${ }^{5}$ King's College \\ Hospital, King's College Hospital NHS \\ Foundation Trust, London, UK; ${ }^{6} \mathrm{~W}$ alsall \\ Manor Hospital, Walsall Healthcare NHS \\ Trust, Walsall, UK; ${ }^{7}$ University Hospital \\ Wales, NHS Wales, Cardiff, UK; \\ ${ }^{8}$ Department of Surgery and Cancer, \\ Imperial College London, London, UK; \\ ${ }^{9}$ Kellogg College, University of Oxford, \\ Oxford, UK
}

\section{Dear editor}

We would like to thank the readership of the journal for their comments pertaining to our paper on "Changing Student Perception of an Online Integrated Structured Clinical Examination During the COVID-19 Pandemic". ${ }^{1}$ Collectively, they have highlighted the timeliness and relevance of our article during the current climate of medical education.

Hazell highlights that mock examinations themselves reduces exam stress among students beyond exam format (in-person or online). ${ }^{2}$ In our majority online examination-naïve participants, it is possible that the experience which combines a mock examination and virtual platform use will improve overall exam anxiety. However, the change scores in Questions 5 and 6 in Table 2 specifically address the online nature of assessments and we had asked two versions of these questions - "If you do not do well" in Question 5 and "If you do well to" in Question 6 to parse the relevance of the examination outcome of students sitting these high stakes examinations if they were indeed conducted online. Since both results show statistical significance, we can confidently extrapolate that our results are beyond that observed from merely sitting a mock examination and the change in perception towards the exam format is key. ${ }^{1}$

We thank Mellers et al for their suggestions to improve our mock experience, however they do not consider the difficulties implementing such suggestions for student societies. ${ }^{3}$ As also described by Mavis et al, choice of standardised patients depends on resource availability. ${ }^{4}$ Having no funding, we had to rely on volunteers among students as standardised patients (who are also likely to gain benefit from participation). We provided these student simulated patients with detailed information, scripts and advice on how to maintain the integrity of these examinations to mimic a real ISCE. Furthermore, nearly 5000 faculty-person hours would have been needed to run this mock and this was a constraint given that their efforts at the time was towards the real ISCEs due in 3 weeks following our student-led mock ISCE.

Mellers et al also suggest that telemedicine experience is an important unaccounted confounder, however we believe experience from formal high-stake examinations/ interviews is significantly different from day-to-day patient communication. ${ }^{5}$ They also suggest the possibility that our mock was too easy, however our mock ISCE was tailored by students and clinicians who had previously sat these examinations at our
Correspondence: Sashiananthan Ganesananthan

National Heart and Lung Institute, Imperial College London, London, UK Email Sashiananthan.Ganesananthan@nhs. net 
institution and were reviewed by senior clinicians including those who have examined in the real examinations. Our excellent individual station feedback shown in Supplementary 2.1-2.4 depict this. ${ }^{1}$

Akhtar et al suggest for open-ended questions on factors associated with worry in an online format, ${ }^{6}$ however we had executed this in our study and found no further themes (depicted in word cloud Supplementary 3.1 and 3.2) beyond our pre-set binary questions, which was created by individuals who have experience from high stakes online examinations/interviews. ${ }^{1}$

Summative clinical examinations at our institution were eventually performed in-person, and this precludes further analysis suggested by Akhtar et al and by Mellers et al to isolate effects of ongoing improved perception change. ${ }^{3,6}$

Nationwide studies of attitudes towards online clinical teaching have already been established. ${ }^{7}$ Given the potential logistical ease of online examinations as a supplement for inperson examinations, now is the right time to similarly address the role of the virtual platform to assess students and institutional collaboration is equally needed to improve the technical stressors (internet connectivity, communication barriers) associated with its implementation. This key stakeholder data will be needed before general implementation of this format for summative clinical assessments.

\section{Disclosure}

The authors report no conflicts of interest in this communication.

\section{References}

1. Ganesananthan S, Li C, Donnir A, et al. Changing student perception of an online integrated structured clinical examination during the COVID-19 pandemic. Adv Med Educ Pract. 2021;12:887-894. doi:10.2147/AMEP.S325364

2. Hazell GA. Changing student perception of an online integrated structured clinical examination during the COVID-19 pandemic [Letter]. Adv Med Educ Pract. 2021;12:1003-1004. doi:10.2147/AMEP. S334594

3. Mellers L, Chelchowska Nicholls-Mindlin J. Changing student perception of an online integrated structured clinical examination during the COVID-19 pandemic [Letter]. Adv Med Educ Pract. 2021;12:1009-1010. doi:10.2147/AMEP.S336118

4. Mavis B, Turner J, Lovell K, Wagner D. Developments: faculty, students, and actors as standardized patients: expanding opportunities for performance assessment. Teach Learn Med. 2006;18(2):130-136. doi:10.1207/s15328015tlm1802_7

5. Van der Vleuten CPM, Schuwirth LWT. Assessing professional competence: from methods to programmes. Med Educ. 2005;39:309-317. doi:10.1111/j.1365-2929.2005.02094.x

6. Akhtar S, Hasan M, Iqbal H. Changing student perception of an online integrated structured clinical examination during the COVID-19 pandemic [Letter]. Adv Med Educ Pract. 2021;12:1005-1006. doi:10.2147/AMEP.S335370

7. Dost S, Hossain A, Shehab M, Abdelwahed A, Al-Nusair L. Perceptions of medical students towards online teaching during the COVID-19 pandemic: a national cross-sectional survey of $2721 \mathrm{UK}$ medical students. BMJ Open. 2020;10(11):e042378. doi:10.1136/ bmjopen-2020-042378

Dove Medical Press encourages responsible, free and frank academic debate. The content of the Advances in Medical Education and Practice 'letters to the editor' section does not necessarily represent the views of Dove Medical Press, its officers, agents, employees, related entities or the Advances in Medical Education and Practice editors. While all reasonable steps have been taken to confirm the content of each letter, Dove Medical Press accepts no liability in respect of the content of any letter, nor is it responsible for the content and accuracy of any letter to the editor.

\section{Publish your work in this journal}

Advances in Medical Education and Practice is an international, peerreviewed, open access journal that aims to present and publish research on Medical Education covering medical, dental, nursing and allied health care professional education. The journal covers undergraduate education, postgraduate training and continuing medical education including emerging trends and innovative models linking education, research, and health care services. The manuscript management system is completely online and includes a very quick and fair peer-review system. Visit http://www.dovepress.com/testimonials.php to read real quotes from published authors. 